\title{
Idiosyncratic Risk and Development in Developing Countries
}

\author{
Minh Quang Dao ${ }^{1, *}$ \\ ${ }^{1}$ Eastern Illinois University, Charleston, IL 61920, USA \\ *Correspondence: Eastern Illinois University, 600 E. Lincoln Avenue, Charleston, IL 61920, \\ USA. E-mail:mqdao@eiu.edu
}

Received: April 22, 2014

doi:10.5296/rae.v6i2.5775
Accepted: May 16, 2014

Published: June 5, 2014

URL: http://dx.doi.org/10.5296/rae.v6i2.5775

\begin{abstract}
This paper examines the impact of idiosyncratic risk management on economic development in developing countries. Based on data from the World Bank, we use a sample of twenty-seven developing economies and find that selected indicators related to risk management at the household level do have a statistically significant effect on economic development in these countries. Regression results show that almost four-fifths of cross-developing country variations in purchasing power parity per capita gross national income can be explained by its linear dependency on the percentage of the population aged over 25 who have completed the tertiary level of education, education quality as measured by the Programme for International Student Assessment reading mean score, the under-five mortality rate, and access to social insurance as measured by the percentage of the population aged 60 and over who are beneficiaries of social insurance.

Statistical results of such empirical examination will assist governments in developing countries identify idiosyncratic risk management strategies that may be used as powerful instruments for economic development.

Keywords: Idiosyncratic Risk Management, Purchasing Power Parity Per Capita GNI, Under-five Mortality Rate, Education Quality, Developing Countries, Educational Attainment, Access to Social Insurance
\end{abstract}




\section{Introduction}

According to the 2014 World Development Report, Risk and Opportunity: Managing Risk for Development, risks that are specific to individuals or households, namely idiosyncratic risks, are as important as systemic risks, which are beyond the means of individuals or households to handle alone, for people's welfare. In particular, for vulnerable families and individuals, job loss or the inability to find one because of lack of adequate skills, being victims of disease or crime, or having one's family broken up due to financial strain or forced migration could be devastating. For example, Dercon, Hoddinott, and Woldehanna (2005) found that households in Ethiopia who have seriously ill members were forced to decrease their consumption by almost 10 percent and went on to be adversely impacted three to five years later. A study by Buvinić and Morrison (2000) shows that health expenses due to high levels of crime and violence account for 0.3 to 5 percent of gross domestic product a year for countries in Latin American, in addition to the effect of crime on lost output from decreased investment and labor participation. According to the 2013 World Development Report: Jobs, not only have income and consumption been lowered, but individuals' ability to find new employment has been reduced, social cohesion has been reduced, and occasionally domestic violence has augmented by the loss of jobs in countries as diverse as Argentina, Bulgaria, and Guyana.

Yet, economic development can take place only if countries can successfully manage risk and purse opportunity. The 2014 World Development Report team conducted benefit-cost analyses across a number of areas and found that risk preparation was beneficial in averting costs. For example, Hoddinott, Rosegrant, and Torero (2012) observed that a diet high in mineral supplements intended to lower malnutrition and its related health hazards might produce benefits at least 15 times higher than the cost of the program. Thus, investments in nutrition and preventive health do make people more productive while at the same time reduce their vulnerability to disease. In recent decades, data from the World Bank's World Development Indicators show that the immunization rate for measles in low- and middle-income developing countries doubled from 41 percent to 83 percent between 1985 and 2010. This improvement, together with other preventive health measures, has resulted in lower infant and maternal mortality rates.

In order for the households to foster resilience and prosperity they need to invest in the human capital and social skills of their members, in particular the young ones, in order to prepare them for the risks and opportunities they will face in the future. However, while the average number of years of educational attainment has increased in all regions since 1960, education quality, as measured by international exams in math and reading skills, is still falling behind in many low- and middle-income countries, so far without any signs of convergence.

The current study empirically examines the effect of selected indicators related to risk management at the household level on economic development. Using data from the World Bank for a sample of twenty-seven(Note 1) developing economies, we find that selected indicators related to risk management at the household level do have a statistically significant 
effect on economic development in these countries. Regression results show that almost four-fifths of cross-developing country variations in purchasing power parity per capita gross national income can be explained by its linear dependency on the percentage of the population aged over 25 who have completed the tertiary level of education, education quality as measured by the Programme for International Student Assessment reading mean score, the under-five mortality rate, and access to social insurance as measured by the percentage of the population aged 60 and over who are beneficiaries of social insurance.

On the other hand, we observe that the percentage of the population aged over 25 who have completed the primary or secondary level of education, education quality as measured by the Programme for International Student Assessment math mean score, the maternal mortality ratio, and the percentage of people aged 15 and over who report saving or setting aside any money in the past 12 months are not statistically significant in explaining economic development in these countries. Statistical results of such empirical examination will assist governments in developing countries identify idiosyncratic risk management strategies that may be used as powerful instruments for economic development.

This paper is organized as follows. In the next section, the formulation of a statistical model to be estimated is presented. Theoretical underpinnings for the inclusion of explanatory variables are presented in this section. Statistical results are reported in the subsequent section. A final section gives concluding remarks as well as policy recommendations.

\section{The Statistical Model}

If we assume that various indicators related to risk management at the household level linearly affect the level of per capita GDP in a developing country, we can state the following statistical model:

$P P P G N I=\beta_{0}+\beta_{1}$ Primary $25++\beta_{2}$ Second $25++\beta_{3}$ Tert $25++\beta_{4}$ PISAmath
$(+)$
$(+)$
$(+)$
$(+)$

$+\beta_{5}$ PISAread $+\beta_{6}$ U5Mortality $+\beta_{7 \text { MatMortal }}+\beta_{8}$ SocIns60+
(+)
(-)
(-)
(+)
$+\beta_{9} \%$ Savings $+\varepsilon$
$(+)$

where $P P P G N I=$ Purchasing Power Parity GNI per capita, in dollars in 2012.

Primary $25+=$ Percentage of the population aged over 25 who have completed primary education, in 2010.

Second $25+=$ Percentage of the population aged over 25 who have completed secondary education, in 2010. 
Tert $25+=$ Percentage of the population aged over 25 who have completed tertiary education, in 2010 .

PISAmath = PISA math mean score, in 2009(Note 2).

PISAread $=$ PISA reading mean score, in 2009.

U5Mortality $=$ Under-five mortality rate, per 1,000 live births, in 2011(Note 3).

MatMortal = Maternal mortality ratio, per 100,000 live births, in 2010(Note 4).

SocIns60 $=$ Percentage of the population aged 60 and over who are beneficiaries of social insurance, various years.

$\%$ Savings $=$ Percentage of people aged 15 and over who report saving or setting aside any money in the past 12 months, in 2011.

$\varepsilon=$ Random error term, with mean 0 and uniform variance.

For most people, a major source of material and emotional support to confront risk and pursue opportunity is the household - defined as a group of individuals related to one another by family ties. We are interested in the effects of households' investment in their members' human capital on development and thus choose to include educational attainment at each level of education as explanatory variable. We expect that the higher the percentage of the population aged over 25 in a developing country who have completed each level of education the higher its level of economic development, as this form of investment in human capital helps prepare young household members to better manage the risks and opportunities they will face in the future.

Similarly, to capture the effect of education quality on development, we include the PISA math and reading mean scores and expect the coefficient estimates of these variables to have a positive sign. On the other hand, a high under-five mortality rate as well as a high maternal mortality ratio, which may result from lack of investments in nutrition and preventive health, is more likely to reduce the labor force, a necessary input in the aggregate production, and hence adversely affect economic development.

The 2014 World Development Report emphasizes managing risks in a pro-active, systematic, and integrated way. These characteristics highlight the important role of forward-looking planning and preparation in the face of uncertainty. This calls for striking a proper balance between the contribution from the state and that from individuals, with the objective of making sure that these contributions are coordinated and complementary. We thus use the percentage of the population aged 60 and over who are beneficiaries of social insurance and that of the population aged 15 and over who report saving or setting aside any money in the past year as means of capturing the effect of these risk indicators on development in developing countries and expect their coefficient estimate to have a positive sign. Data for all variables are from the 2012 and 2014 World Development Reports and the 2013 World Development Indicators. 


\section{Empirical Results}

Table 1 gives least-squares estimates of regression coefficients in equation (1) for a sample of twenty-seven developing economies. The goodness of fit of the model to the data is very good as indicated by the value of 0.746 of the adjusted coefficient of determination. We observe that only one explanatory variable is statistically significant, namely the percentage of the population aged over 25 who have completed the tertiary level of education and that its coefficient estimate does have the anticipated positive sign. As this segment of the population increase by one percentage point, we would expect a three hundred and forty-six-dollar decrease in purchasing power parity gross national income per capita, other things being equal. We suspect that a major explanation for this finding is due to the high degree of multicollinearity among explanatory variables.

Table 1. Empirical results (full model)

\begin{tabular}{lcc}
\hline & Coefficient Estimates & $t$-Statistics \\
\hline Intercept & -26046.775 & -1.685 \\
Primary25+ & 58.562 & 0.737 \\
Second25+ & 44.862 & 0.645 \\
Tert25+ & 345.996 & $2.624 *$ \\
PISAmath & 30.204 & 0.440 \\
PISAread & 53.358 & 0.722 \\
U5Mortality & -195.525 & -0.731 \\
MatMortal & 3.725 & 0.089 \\
SocIns60+ & 25.054 & 0.792 \\
\%Savings & 29.734 & 0.409 \\
\hline
\end{tabular}

Adjusted $\mathrm{R}^{2}=0.746$

*Significant at the 1 percent level.

Using the backward elimination stepwise method we arrive at a revised model, the regression results of which are reported in Table 2. We note that the goodness of fit of the model to the data is better as indicated by the higher value of 0.789 of the adjusted coefficient of determination. We observe that all four explanatory variables are statistically significant at the 10 percent or lower level and that their coefficient estimates do have their expected sign.

The impact of the percentage of the population aged over 25 who have completed the tertiary level of education on per capita GDP has been reduced to $\$ 323$ for every percentage point increase in the value of this variable. The under-five mortality rate variable is now statistically significant at the 10 percent level, and its coefficient estimate has the expected negative sign. All else equal, a one-percentage point increase in the probability that a newborn baby will die before reaching age five, if subject to the age specific mortality rates of that year, is expected to lead to a $\$ 195$ dollar decrease in per capita GDP. We also observe that as the PISA mean reading score in a developing country increases by a point, it is expected that per capita purchasing power parity GNI will increase by $\$ 85$, ceteris paribus. Finally, a one percentage point increase in the percentage of the population aged 60 and over 
who are beneficiaries of social insurance is expected to lead to an increase of $\$ 33$ in per capita gross national income, all else equal.

Table 2. Empirical results (revised model)

\begin{tabular}{lcc}
\hline & Coefficient Estimates & t-Statistics \\
\hline Intercept & -23666.895 & -1.909 \\
Tert25+ & 323.008 & $2.862^{*}$ \\
PISAread & 84.689 & $3.429^{*}$ \\
U5Mortality & -194.842 & $-1.392^{* * *}$ \\
SocIns60+ & 32.872 & $1.750^{* *}$ \\
\hline
\end{tabular}

Adjusted $\mathrm{R}^{2}=0.789$

*Significant at the 0.5 percent level.

**Significant at the 5 percent level.

***Significant at the 10 percent level.

\section{Conclusion}

In this paper we use a statistical model and data from a sample of twenty-seven developing economies to empirically analyze the impact of selected indicators related to risk management at the household level on the level of per capita GNI. From the statistical results we are able to draw the following conclusions:

1. Within the set of developing economies in this study, the higher the percentage of the population aged over 25 who have completed the tertiary level of education, the higher its level of per capita income. Governments in these countries need to implement policies aimed at encouraging a larger segment of their population to achieve the tertiary level of education.

2. Developing countries in which their students have access to education quality tend to have a higher level of per capita income. Governments in these countries need to find ways of improving the mean reading performance of all their students. This, in turn, is expected to stimulate economic development.

3. Developing countries that have a higher under-five mortality rate do experience a lower level of development. Efforts should then be aimed at providing more immunizations against diseases most likely to be inflicted upon children under the age of five while increasing access of their citizens to improved sanitation facilities.

4. Developing countries in which there is a large proportion of their population aged 60 and over who are beneficiaries of social insurance are more likely to have a higher level of economic development. Governments in these countries thus need to put in place social insurance programs designed to provide a safety net for the aged as the latter may be most vulnerable to the effect of adverse shocks such as health and weather shocks as well as economic crises. 


\section{Acknowledgment}

I would like to thank the editor of Research in Applied Economics and an anonymous reviewer for their comments on and suggestions for an earlier version of this paper and Thi Minh Chi Le for her support during the completion of this paper.

\section{References}

Buvinić, M., \& Morrison, A.R. (2000). Living in a More Violent World. Foreign Policy, (118), 58-72. http://dx.doi.org/10.2307/1149670

Dercon, S., Hoddinott, J., \& Woldehanna, T. (2005). Shocks and Consumption in 15 Ethiopian Villages, 1994-2004. Journal of African Economies, 14(4), 559-85. http://dx.doi.org/10.1093/jae/eji022

Hoddinott, J., Rosegrant, M., \& Torero, M. (2012). "Investments to Reduce Hunger and Undernutrition," Paper prepared for the 2012 Global Copenhagen Consensus.

World Bank (2013). World Development Indicators 2013. World Bank, Washington, DC. http://data.worldbank.org/data-catalog/world-development-indicators

(2011). World Development Report 2012: Gender Equality and Development. Washington, DC: World Bank.

(2012). World Development Report 2013: Jobs. Washington, DC: World Bank.

(2013). World Development Report 2014: Risk and Opportunity: Managing Risk for Development. Washington, DC: World Bank.

\section{Notes}

Note 1. The sample consists of the following countries: Albania, Brazil, Bulgaria, Chile, Colombia, Croatia, Czech Republic, Greece, Hungary, Indonesia, Jordan, Kazakhstan, Kyrgyz Republic, Lithuania, Mexico, Panama, Peru, Poland, Portugal, Romania, Russian Federation, Serbia, Slovak Republic, Thailand, Tunisia, Turkey, and Uruguay.

Note 2. The Programme for International Student Assessment (PISA) is an internationally comparable student assessment, coordinated by the OECD. The assessment has evaluated the knowledge and skills of 15 year olds by testing reading, mathematical, and scientific literacy every three years since 1997. Mean performance by subject refers to the average score of all students' scores in that country.

Note 3 . The under-five mortality rate is the probability that a newborn baby will die before reaching age five, if subject to the age specific mortality rates of that year.

Note 4. The maternal mortality ratio is the number of women who die from pregnancy related causes while pregnant or within 42 days of pregnancy termination. 


\section{Copyright Disclaimer}

Copyright reserved by the author(s).

This article is an open-access article distributed under the terms and conditions of the Creative Commons Attribution license (http://creativecommons.org/licenses/by/3.0/). 